\title{
COST-TIME PROFILE SIMULATION FOR JOB SHOP SCHEDULING DECISIONS
}

\author{
Gracanin, D. ; Lalic, B. ; Beker, I. ; Lalic, D. ${ }^{*} \&$ Buchmeister, B. ${ }^{* *}$ \\ "University of Novi Sad, Faculty of Technical Sciences, Trg Dositeja Obradovica 6, 21000 Novi Sad, \\ Serbia \\ ${ }^{* *}$ University of Maribor, Faculty of Mechanical Engineering, Smetanova 17, 2000 Maribor, Slovenia \\ E-Mail: gracanin@uns.ac.rs
}

\begin{abstract}
Manufacturers have to look constantly for new strategies and tools to improve processes, decrease cost and increase productivity and efficiency. Production scheduling is one of the crucial elements in manufacturing and has an impact on delivery deadlines and also on the production process in terms of its utilization. On the other hand, the value stream optimization is very important for lean manufacturing efforts. This paper is aimed to research the impact of job shop scheduling on value stream optimization and decreasing of cost-time investment. Value stream mapping represents a very efficient tool for visualization of activities within production flow focused on activity duration with the purpose to eliminate non-value added activities. Value stream costing is based on value stream and eliminates the need for overhead allocation and calculation. Cost-time profile is a powerful tool for visualization and calculation of cost accumulation during the time across the entire manufacturing flow. Software tools used in this paper are: Lekin scheduling system for constructing the schedules based on four different dispatching rules and Cost-Time Profiler software for simulating the impact of different schedules on total production cost and cost-time investment (representing the time value of money), which is proposed as a new scheduling objective function.

(Received in August 2012, accepted in June 2013. This paper was with the authors 3 months for 1 revision.)
\end{abstract}

Key Words: Cost-Time Profile, Lean Manufacturing, Value Stream Costing, Scheduling, Cost-Time Investment Simulation

\section{INTRODUCTION}

Modern business global market conditions are forcing manufacturers to increase competitiveness, which can be achieved by developing flexible manufacturing systems, producing high quality products and reducing production costs. At the same time, manufacturers have to pay more attention to product variety, customer value and delivery deadlines, because era of mass production is over. In order to increase production effectiveness, companies could choose strategy of continuous improvement through waste elimination. Efficient production process coupled with high quality control has become essence for manufacturing companies to guarantee on-time delivery and meet customers' satisfaction [1].

Time and cost reduction is imperative for every company, so monitoring and control of manufacturing cost over the time can be a good base for improvements. Time is money and using less consumable in manufacturing could be a good strategy for money making and money savings could also be achieved by preventing waste [2].

In modern economy customer value is the priority, as well as measuring the cost of resources usage and productivity. Higher output and higher productivity are achieved with overall added value by lead time reduction, so manufacturers have to develop processes which could create its added value as fast as possible [3]. Simultaneously with implementation of 
modern manufacturing approaches, companies have to change business procedures in general in order to be compatible with new manufacturing philosophy [4-5]. Internal and external information are the most important resources in modern business environment, so collecting information in the right way and in real time is a big challenge for companies. Collecting information from manufacturing processes is mainly adapted for mass production, and product cost is the crucial fact for management. Many companies are not able to identify and recognize the complete value stream.

In the paper we are giving a brief literature review of publications dealing with lean manufacturing and value stream mapping, lean accounting and value stream costing, cost-time profile and job shop scheduling basics (section 2), continued with the scheduling problem definition (section 3) and the results' discussion (section 4). Finally, section 5 contains a conclusion of the work and the future work.

\section{LITERATURE REVIEW}

Literature review has been done with respect to two different research areas. The first is the value stream costing and its roots in lean manufacturing and value stream mapping, and the second one is the cost-time profile as a tool for visualization and calculation of cost-time investment.

\subsection{Lean manufacturing and value stream mapping}

Global competition is forcing many companies to adopt new approaches to production such as lean manufacturing in order to be more competitive. Today, lean production represents every effort to achieve greater effects with less investment. Since lean production is a multidimensional approach that groups together a wide range of management practices (including Just-In-Time, total quality management, working groups, one-piece flow, customer relationship management) in one integrated system and, if these elements are properly implemented, generates synergy and creates a high quality system with the level of production, which is adjusted according to the customer requirements without waste [6].

Lean manufacturing or Toyota production system is comprehensive set of tools and techniques for waste elimination with the aim to improve flexibility and effectiveness of a production system [7]. Also, Ohno said that the basis of lean production is absolute waste elimination and the main goals are cost reduction and increasing production system efficiency [8]. He explained problems that Toyota had after the Second World War with limited resources and Toyota Production System is the answer how to use resources in a best way.

Womack et al. presented results of five years study performed and managed by Massachusetts Institute of Technology in a well-known book "The machine that changed the world", in which they emphasised the elements that make Toyota Production System more superior than mass production [9]. They believe that lean production will supplant mass production and other manufacturing approaches in all industrial areas and become a standard global production system of the $21^{\text {st }}$ century. Maskell and Kennedy pointed out the necessity of lean management philosophy implementation derived from the needs of companies to increase productivity, reduce costs, increase flexibility and create more value for the customer, and on that way increase the overall performance, cash flows and value stocks [10]. Lanza et al. concluded that the main drivers for lean production implementation are costs and faulty parts reduction, as well as meeting of production deadlines [11].

Survey conducted by Allied Consultants Europe in 2008 about operational and lean management highlighted that companies which have applied lean philosophy in its processes have a good platform for improvement and significant increase of chances to become top 
producers characterized by on-time delivery of high quality products, high level of readiness to accept changes, a well-defined long-term objectives in line with the vision of company [12].

Pettersen analysed definitions of lean production, and interesting results of his research work are the lists of goals which lean production should meet and frequently mentioned characteristics of lean in books and scientific papers [13]. So, some of the lean production goals are: making products with fewer defects to precise customer desire, customer value improving and waste reducing, customer focus, one-piece flow and continuous improvement.

As we can see, customer value is mentioned few times, so companies should put customer value as one of the most important priorities. Womack and Jones said that customers compare value of money with the value they get for that money. So, customer is ready to pay for value, but won't to pay for expenses and wastes which manufacturer had during the value creation [14]. Malta and Cunha argue that the customer value can be increased by reducing waste in the processes through projects of continuous improvement embedded in lean management principles, which implementation promises significant improvements in productivity, quality and delivery. All above mentioned should lead to cost savings [15]. Also they said that companies should know how customer defines value and creating more value for customer can be very effectively achieved through defining, understanding, monitoring and improving the value stream.

Besides orientation on customer value, lean manufacturing puts the emphasis on material flow, from the moment when material enters in the process to the moment when product is ready for the market [16]. Luyster and Tapping confirm that lean manufacturing starts and ends with a customer, and before any changes, companies must understand what customer needs. They also suggest to companies to map value stream in order to see sources of waste and value, as well as to make value flow for customer [17].

Rother and Shook started writing of their book "Learning to see" with the next sentence: Whenever there is product for customer, there is a value stream and the challenge lies in seeing it [18]. They defined value stream as all the action, value added and non-value added, necessary to bring product through production flow (from raw material to the customer) and design flow (from concept to launch). Value stream mapping is an essential tool for processes visualization that helps to understand material and information flows and see more than waste. The main goals of value stream management are: waste elimination from the production processes and operation, reducing the time in the processes, cost reduction and quality improvement [19]. Lee and Snyder remind that only visual effects provide information for understanding the pieces, relationships, and the hidden waste. Visualisation leads to deeper understanding of productivity and other performances [20].

\subsection{Lean accounting and value stream costing}

Many companies had failure with implementation of lean production, because the traditional accounting system is not based on lean principles and doesn't provide appropriate and timely information [21]. Traditional accounting system is designed to support mass production, oriented to product, organized by departments and doesn't make difference between direct and indirect costs. Kaplan identified that traditional cost accounting system is based on an assumption of long production runs of a standard product, with unchanging characteristics and specifications and will not be applicable for new business conditions and environment [22]. In order to avoid potential conflicts with the lean implementation, companies are beginning to implement other accounting system such as activity-based costing or lean accounting, and these systems are oriented to solving the problem of overhead allocation.

Cooper and Kaplan developed activity-based costing guided by the idea that all company's activities exist to support the production and delivery of goods and services [23]. So, all costs 
are assigned to each activity that participates in product manufacturing including indirect costs. But, Velmurugan found that activity-based costing is not widely adopted since its introduction in $1980 \mathrm{~s}$, because it is too complicate to collect information, as well as to monitor the changes in activities. He concluded that administrative and technical complexities are the main reasons of rejection of this accounting model [24].

Lean accounting was developed to support the implementation of lean manufacturing based on value stream mapping. All costs become direct; their allocation along the value stream is shown in Fig. 1 [25].

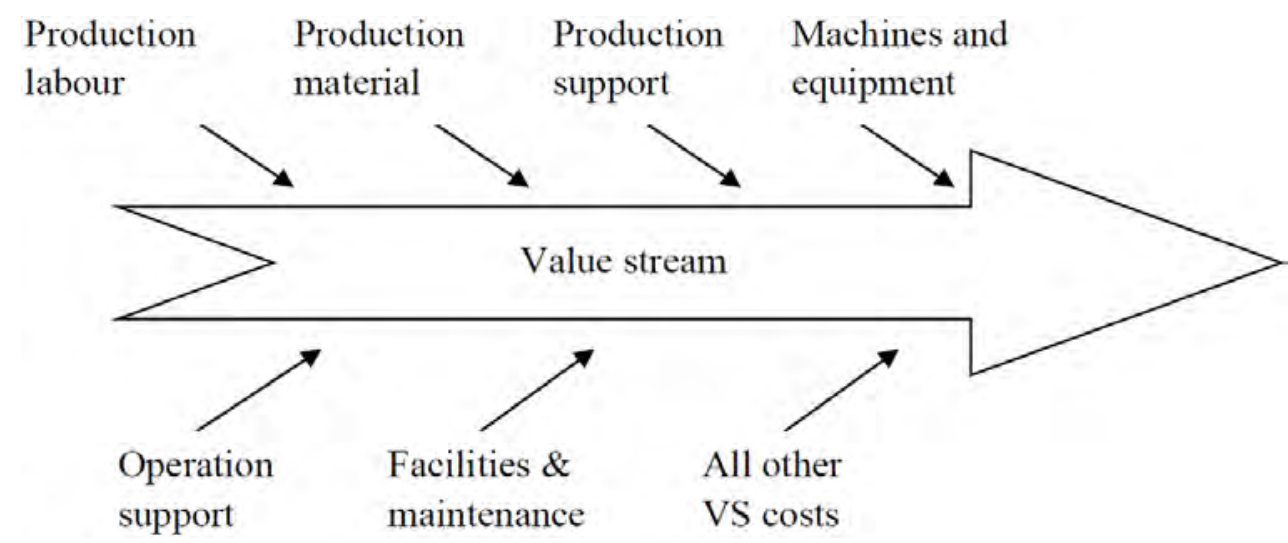

Figure 1: Cost of value stream [25].

\subsection{Cost-time profile}

The term cost-time profile was first time mentioned by Fooks in his book "Profiles for Performance". Cost-time profile is a technique developed in Westinghouse Electric Corporation as a response to the question: how to measure process improvements or how to select the right decision, which measure should be applied in order to improve process. Fooks defined cost-time profile as a diagram of cash accumulation during each unit of time across the entire business cycle (from negotiating an order and entering it, to pre-manufacturing design and information gathering processes through manufacturing, to shipment and receivables) and this profile is a cash oriented diagram [26].

The foundation of cost-time profiling rests on the idea that any business activity can be viewed as an accumulation of cost over time. In other words, the cost-time profile is a graph that shows how much money was spent for the production of the product and how much time elapsed from process start to end, until the money came back through the sale [27]. Cost-time profile discovers new opportunities for improvement and helps, how to evaluate and select measures to achieve the improvement.

Cost-time profile diagram needs information about process, cost and activities and regardless of the production process type and its complexity has three components (as shown in Fig. 2): (1) material (including services and information), (2) labour and (3) wait [28]. Labour component could be named "activity", because it refers to activity performing.

\subsection{Job shop scheduling}

If completion of job is successful, probably means that performing of job was within planned time. All activities, operations and processes in one company have to be scheduled in order to meet production and sales plans. Scheduling is one of the most important tools in production planning and control, because it defines arrangement of activities in order to utilise time, as a major constraint, in optimal manner and companies have to develop good scheduler in order 
to be able to satisfy changeable customer needs [29]. It is also extremely hard problem because it requires very large combinatorial search space and the precedence constraints between machines [30]. Dispatching rules determine the processing sequence of jobs waiting in the queues of corresponding machines and the main goals are optimization of due date attainment, flow time and facilities utilisation [31]. On the other side, the value stream mapping for a job shop environment should be flexible to deal with the dynamic nature of job shops [32].

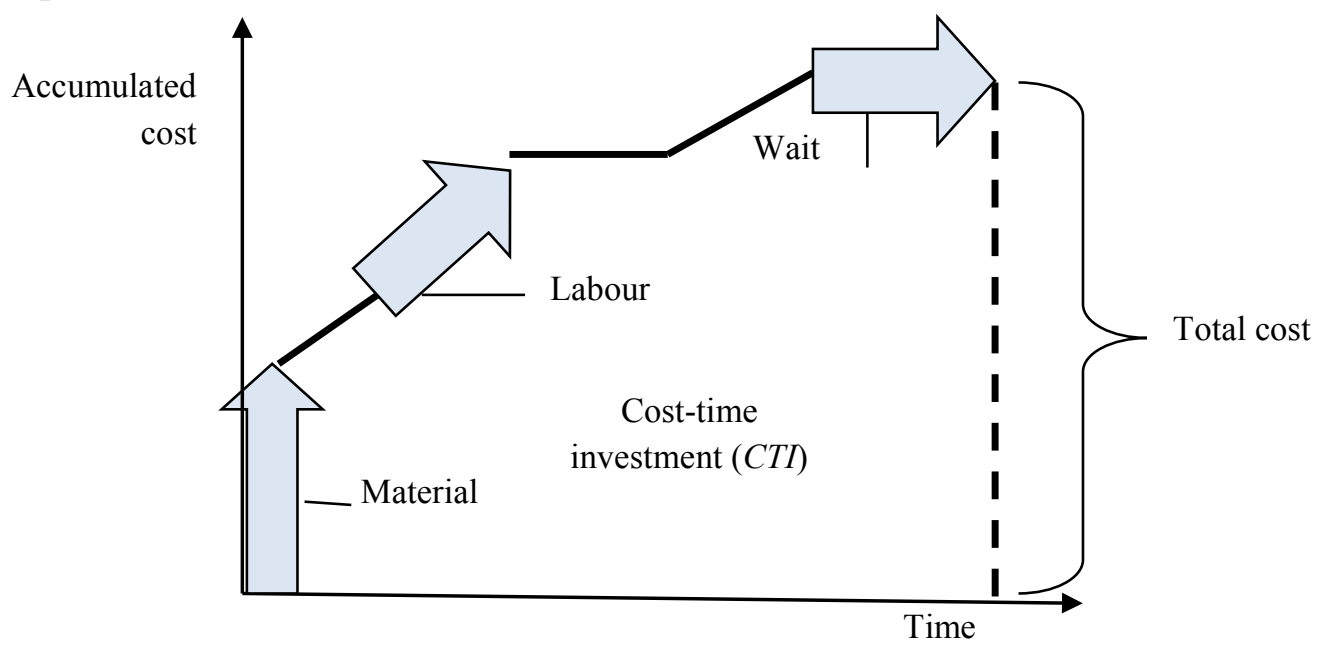

Figure 2: Cost-time profile diagram.

\section{PROBLEM DEFINITION}

Our previous work was focused on research how changes in cost of material, cost of operation and time when material enters in production system cause changes in total cost and cost-time investment. This paper intends to investigate the impact of changes in schedules on decreasing of total cost and cost-time investment. In other words, we now include cost dimension of scheduling which depends on beginning time of jobs and how long they are performing. Value stream mapping and job shop scheduling have similar goals: to decrease lead time and production cost as well as to increase customer value. On the other side, costtime profile has aim to show cost accumulation during the time, so we used this tool to simulate different scenarios after implementation of different schedules.

We started with the generating of 10 data sets for a job shop consisting of five machines and seven jobs (all with the same weight) in each data set. We have examined all 10 variants and the results were similar, so in this paper we present just one, representative sample - see the data given in Table I. Rows in the right column contain the order of the operations for each job: each entry contains the index of machine and the processing time $\left(p_{i j}\right)$ on it.

Table I: Input data for scheduling (sample).

\begin{tabular}{|c|c|c|rcccc|}
\hline Jobs & Release date & Due Date & \multicolumn{4}{|c|}{ Machines/Processing Times } \\
\hline $\mathrm{A}$ & 0 & 39 & $1 / 7$ & $2 / 6$ & $3 / 8$ & $4 / 9$ & $5 / 4$ \\
\hline $\mathrm{B}$ & 0 & 42 & $2 / 3$ & $1 / 8$ & $5 / 3$ & $3 / 8$ & $4 / 9$ \\
\hline $\mathrm{C}$ & 0 & 41 & $3 / 3$ & $2 / 7$ & $1 / 7$ & $5 / 9$ & $4 / 7$ \\
\hline $\mathrm{D}$ & 0 & 41 & $2 / 3$ & $1 / 4$ & $3 / 9$ & $4 / 3$ & $5 / 3$ \\
\hline $\mathrm{E}$ & 0 & 36 & $2 / 5$ & $3 / 4$ & $5 / 4$ & $4 / 2$ & $1 / 7$ \\
\hline $\mathrm{F}$ & 0 & 40 & $2 / 9$ & $1 / 2$ & $3 / 8$ & $4 / 9$ & $5 / 6$ \\
\hline $\mathrm{G}$ & 0 & 38 & $5 / 8$ & $2 / 9$ & $4 / 6$ & $3 / 2$ & $1 / 3$ \\
\hline
\end{tabular}


Analysis of the sample data shows that we are using very tight due dates $\left(d_{i}\right)$ to reflect the differences better. Due dates are related to the total work content $\left(d_{i}=r_{i}+k_{w} \sum p_{i j}\right.$, where $r_{i}$ is a release date and $k_{w}$ is a due date allowance coefficient, 1.36 on average).

We used these input data to calculate the beginning and the end time for each of these 7 jobs. Dispatching rules applied for this research were: Earliest Due Date (EDD), Critical Ratio (CR), Minimum Slack First (MS) and Shortest Processing Time (SPT). For this stage of research we used Lekin scheduling system to construct the schedules. Scheduling results are given in Table II.

Table II: Output data from Lekin software.

\begin{tabular}{|c|c|c|c|c|c|c|c|c|}
\hline \multirow{3}{*}{ Job } & \multicolumn{9}{|c|}{ Dispatching rule } \\
\cline { 2 - 9 } & \multicolumn{2}{|c|}{ EDD } & \multicolumn{2}{c|}{ CR } & \multicolumn{2}{c|}{ MS } & \multicolumn{2}{c|}{ SPT } \\
\cline { 2 - 9 } & Start & End & Start & End & Start & End & Start & End \\
\hline A & 0 & 41 & 0 & 72 & 0 & 51 & 7 & 48 \\
\hline B & 41 & 90 & 9 & 77 & 9 & 59 & 30 & 77 \\
\hline C & 0 & 74 & 0 & 54 & 0 & 66 & 0 & 64 \\
\hline D & 31 & 70 & 39 & 62 & 39 & 72 & 0 & 22 \\
\hline E & 0 & 22 & 25 & 57 & 25 & 57 & 3 & 37 \\
\hline F & 22 & 58 & 0 & 48 & 0 & 47 & 33 & 92 \\
\hline G & 0 & 33 & 0 & 50 & 0 & 60 & 0 & 30 \\
\hline
\end{tabular}

In order to visualise schedule and show how different rules cause different lead time, we present Gantt charts for above mentioned dispatching rules (see Fig. 3 a-d; rows show the utilisation of machines 1 to 5). In Table III, we present the summary of the various performance measures of the schedules.
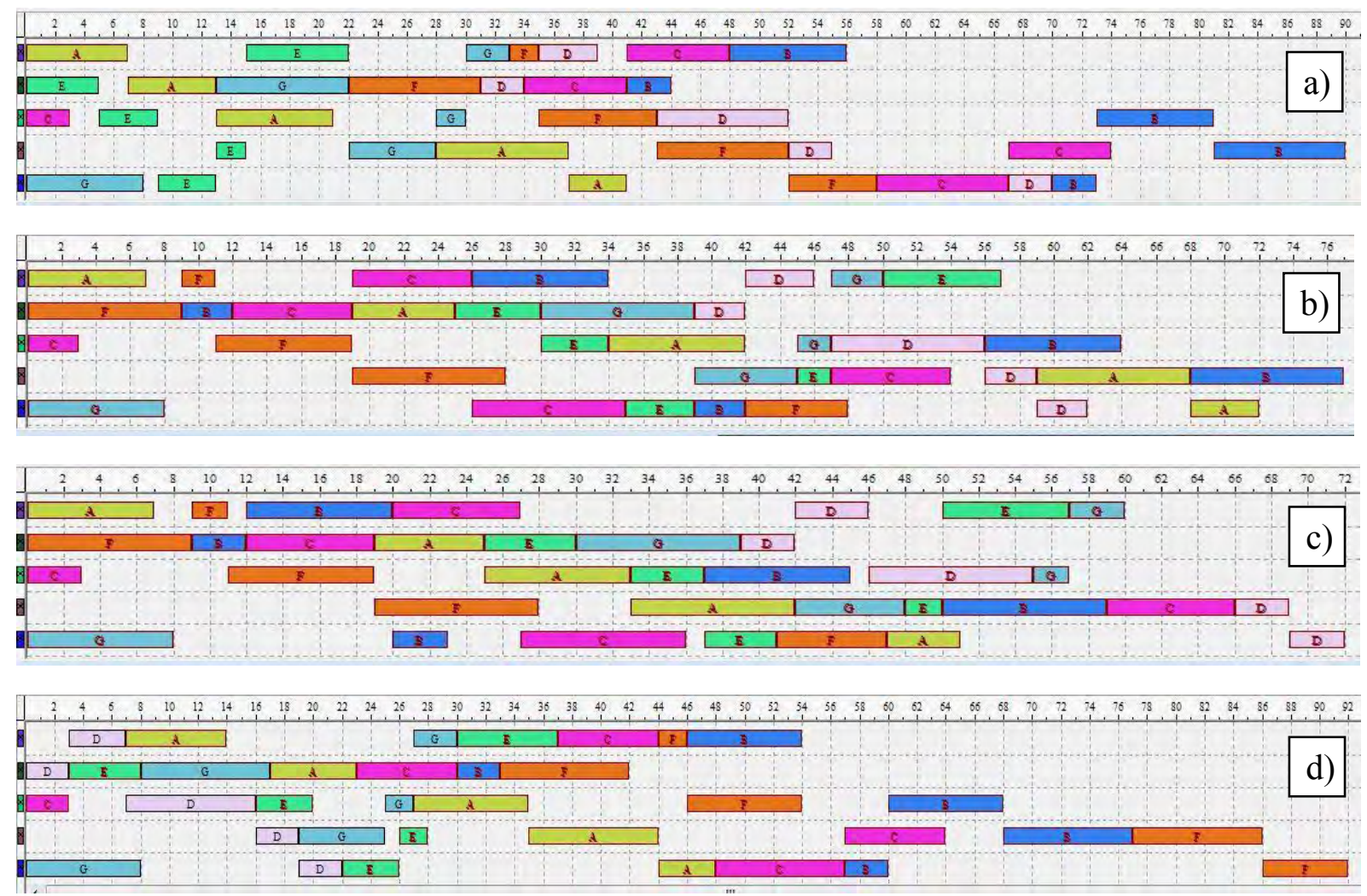

Figure 3: Gantt charts for applied rules, a) EDD rule, b) CR rule, c) MS rule, d) SPT rule. 
Table III: Summary of the various performance measures of the schedules.

\begin{tabular}{|c|c|c|c|c|c|}
\hline Rule & $\boldsymbol{C}_{\boldsymbol{m a x}}$ & $\boldsymbol{T}_{\max }$ & $\sum \boldsymbol{U}_{\boldsymbol{i}}$ & $\sum \boldsymbol{C}_{\boldsymbol{i}}$ & $\sum \boldsymbol{T}_{\boldsymbol{i}}$ \\
\hline $\mathrm{EDD}$ & 90 & 48 & 5 & 388 & 130 \\
\hline $\mathrm{CR}$ & 77 & 35 & 7 & 420 & 143 \\
\hline $\mathrm{MS}$ & 72 & 31 & 7 & 412 & 135 \\
\hline $\mathrm{SPT}$ & 92 & 52 & 5 & 370 & 120 \\
\hline
\end{tabular}

$C_{\max }-$ makespan (completion time of all jobs),

$T_{\max }$ - maximum tardiness,

$\sum U_{i} \quad$ - total number of tardy jobs,

$\sum C_{i} \quad$ - total flow time,

$\sum T_{i} \quad$ - total tardiness.

In the next step we calculated and simulated the cost-time profiles and cost-time investments under different conditions, defined by the schedules. Software used for this purpose is Cost-Time Profiler (developed in 2006 by a project team from Virginia Tech Centre for High Performance Manufacturing - CHPM) for data capture, calculations and graphic output. Beside data of start and end time for each job, we had to assign other relevant data such as material $\operatorname{cost} C_{m}$ and labour $\operatorname{cost} C_{l}$ for each job, respecting value stream costing rules. Fig. 4 shows two screens for data entry.
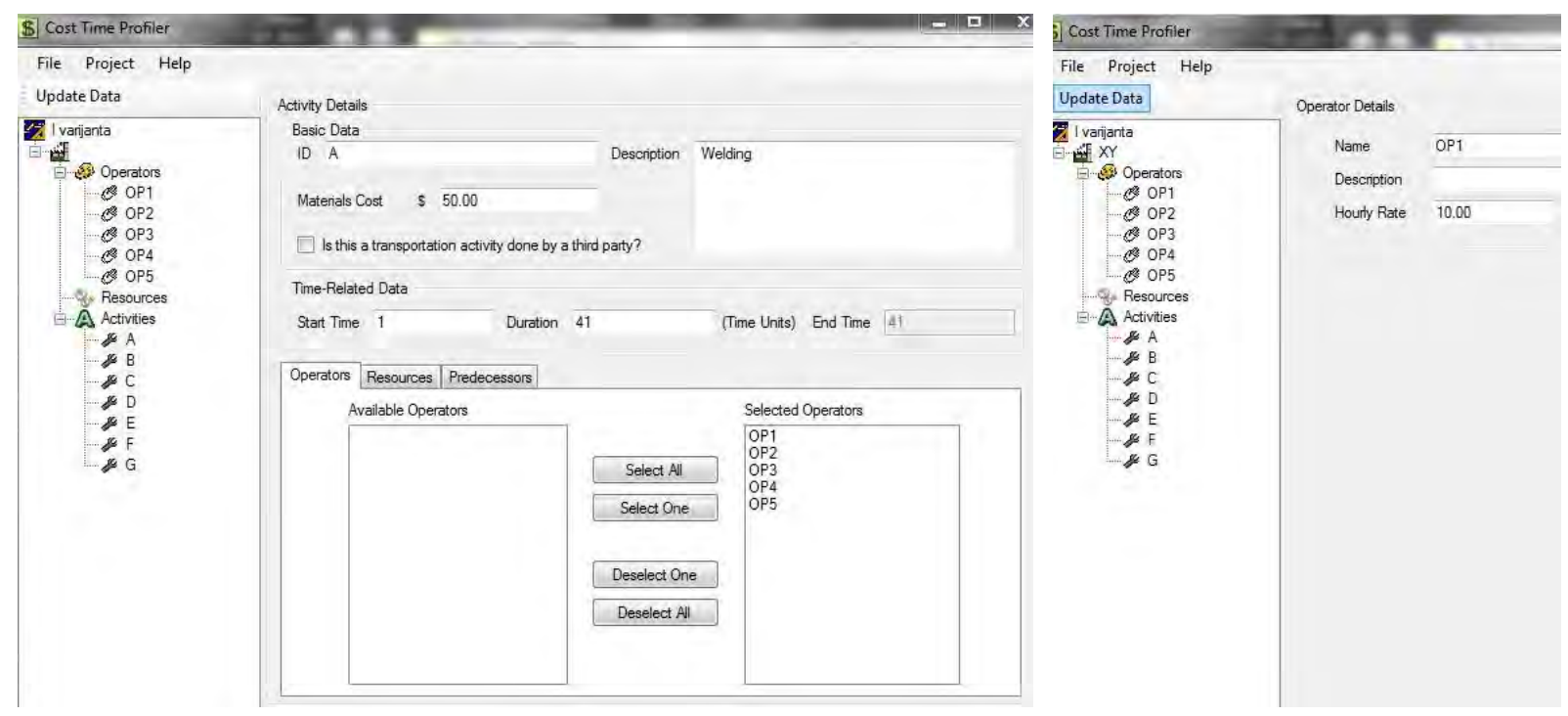

Figure 4: Cost-Time Profiler screens for data entry.

Data obtained as results from Lekin software, for all four dispatching rules, have been used for determination of start time and processing time for each job. Fig. 1 shows which costs have to be taken into consideration, when we analyse value stream cost. But, for this research, our primary goal was to prove that scheduling has certain impact on investment, so we selected just labour and material cost as representative. This could be recognized as one of the constraints for this research. For each job, we assigned material cost $C_{m}$ (in US\$): $C_{m \mathrm{~A}}=50$, $C_{m \mathrm{~B}}=40, C_{m \mathrm{C}}=35, C_{m \mathrm{D}}=50, C_{m \mathrm{E}}=30, C_{m \mathrm{~F}}=50$ and $C_{m \mathrm{G}}=40$. Each job has been performed by five operators and their hourly rates $C_{l}$ were (in US\$): $C_{l \mathrm{OP} 1}=10, C_{l \mathrm{OP} 2}=12, C_{l \mathrm{OP} 3}=15$, $C_{l \mathrm{OP} 4}=15$ and $C_{l \mathrm{OP} 5}=10$. For the next research, we are planning to use machines related data such as: price, life (in years), maintenance cost and daily usage (in hours). 
Results of performed calculation and cost-time profile simulation are presented in the next four figures.

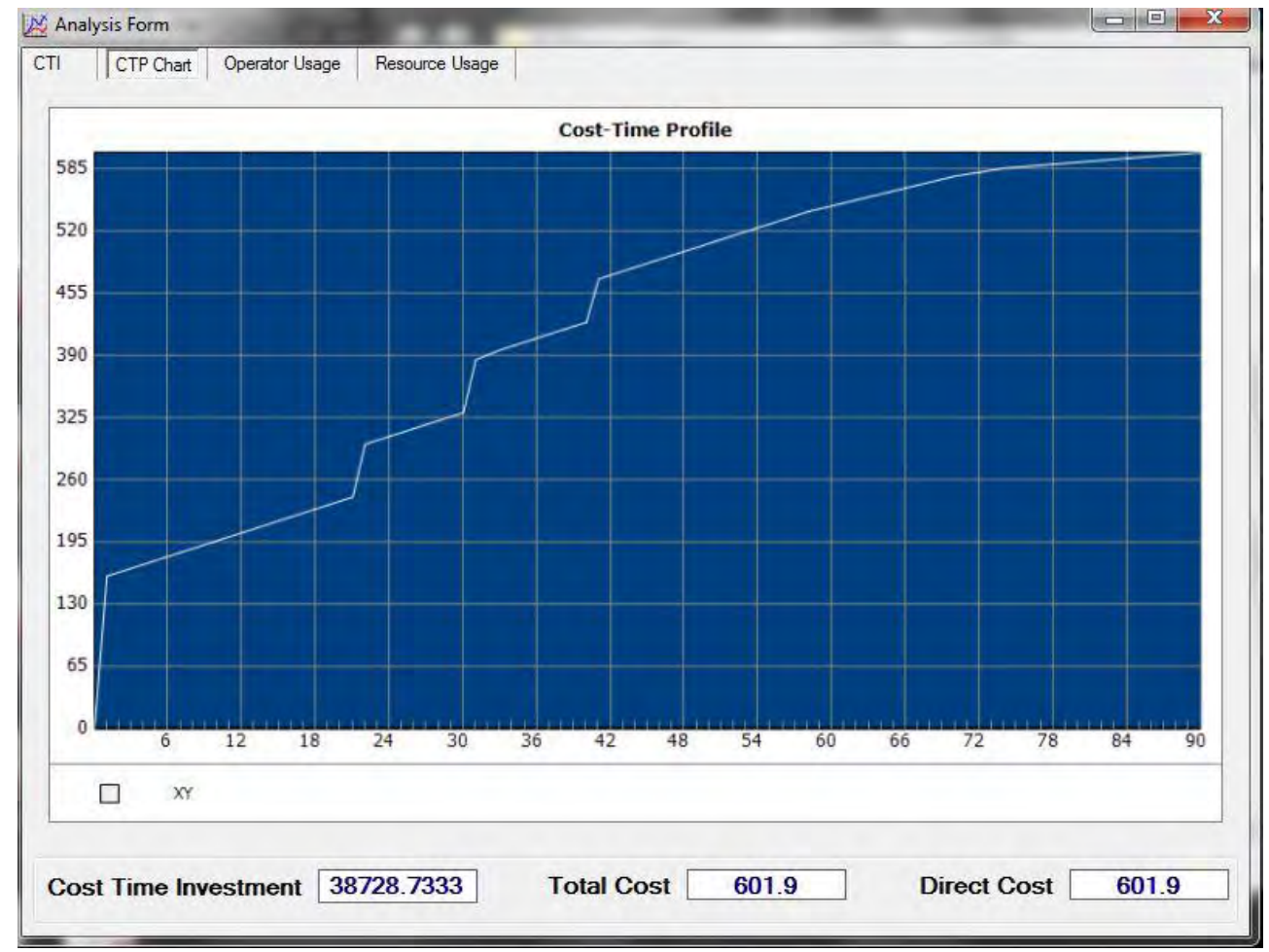

Figure 5: Cost-time profile for the EDD dispatching rule.

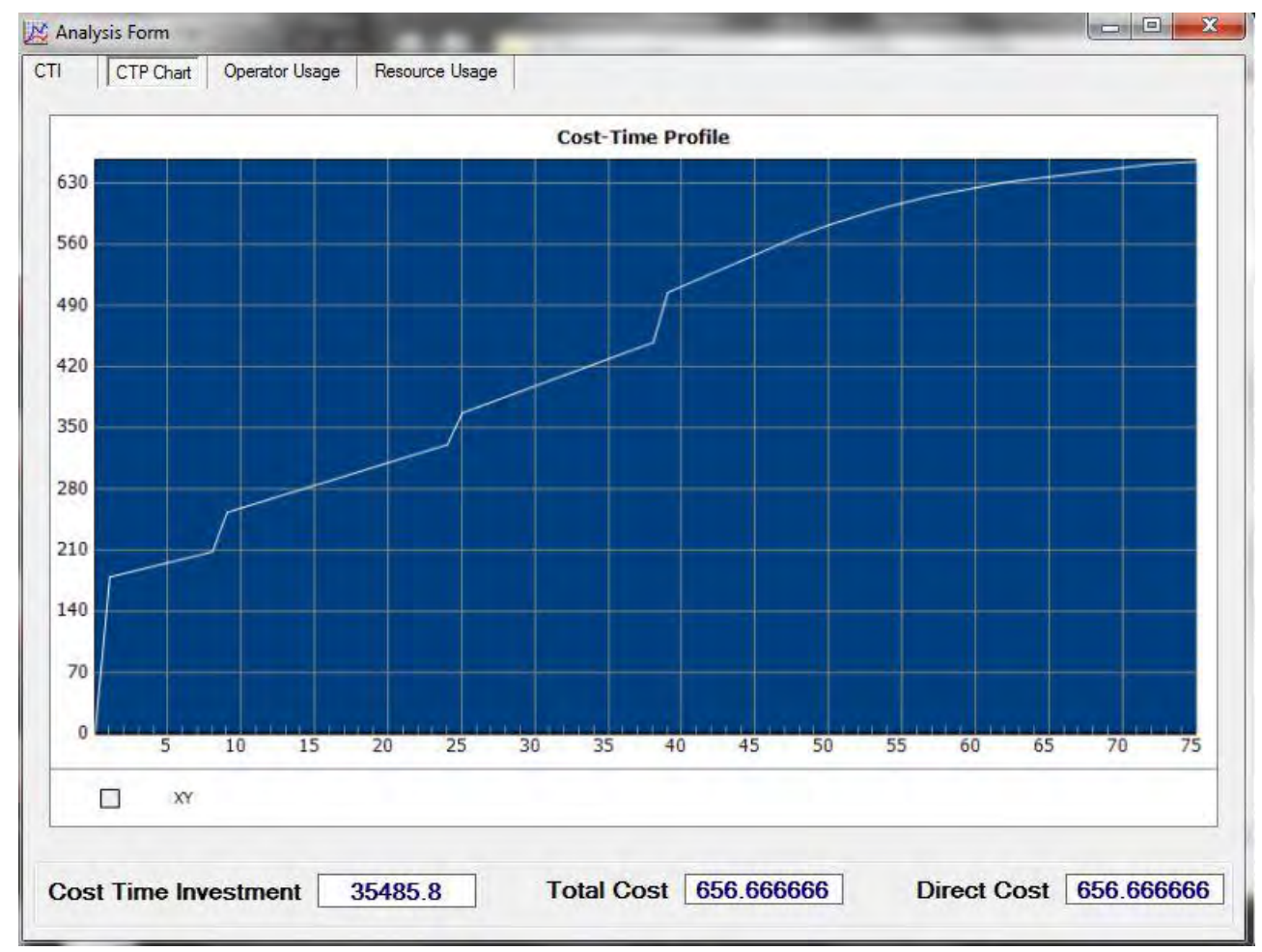

Figure 6: Cost-time profile for the $\mathrm{CR}$ dispatching rule. 


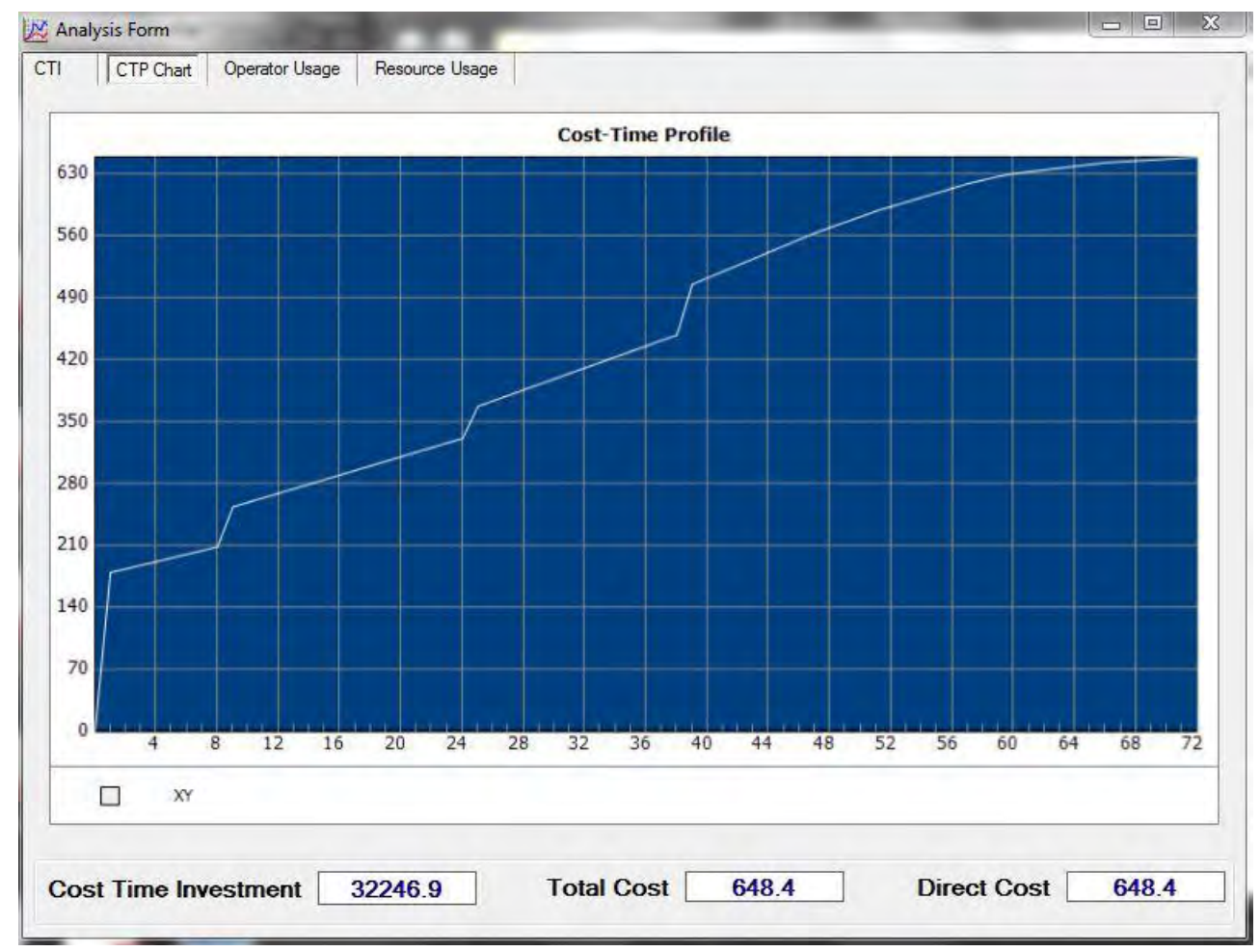

Figure 7: Cost-time profile for the MS dispatching rule.

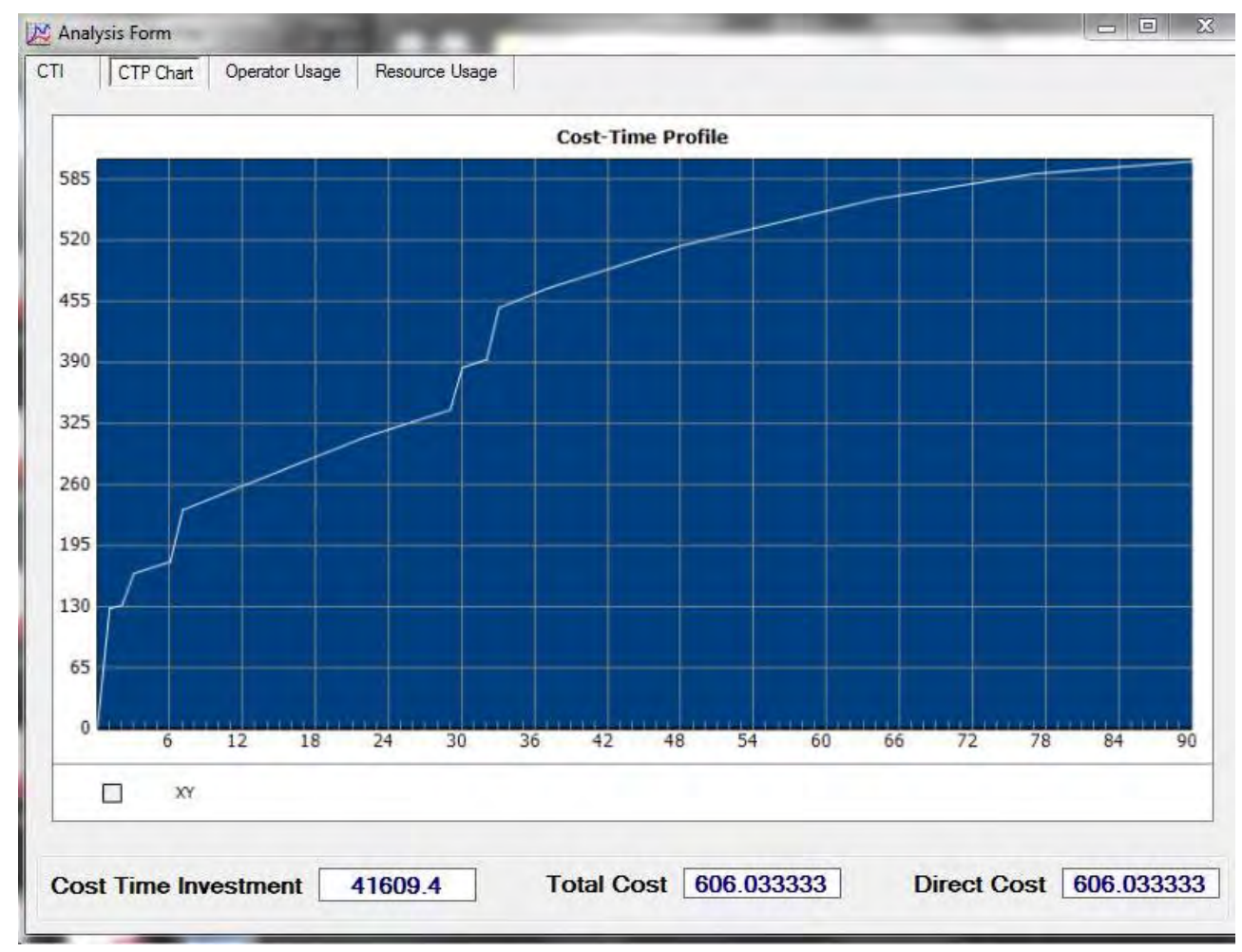

Figure 8: Cost-time profile for the SPT dispatching rule.

\section{DISCUSSION}

When we are calculating cost-time investment $C T I$, the main goal is to decrease the area under the curve or to add most of the value at the end of the process in order to turn added 
values into money as soon as possible. Figs. 5 to 8 show that different dispatching rules cause different values of cost-time investment and total cost. After the analysis of proportion between minimum and maximum values of cost-time investment, we find out a big difference, almost $30 \%$. This is a really significant indicator and it could be a very useful tool for value stream optimization. We were also calculating cost-time investment for the remaining 9 variants, and results were similar, so we can confirm that scheduling, besides the influence on makespan, deserves to be considered from the aspect of cost.

Let's compare the rules' performances! According to the makespan objective function $C_{\max }$ and to the maximum tardiness $T_{\max }$ the best of four compared rules was the MS rule; for the total number of tardy jobs $\sum U_{i}$ the EDD and SPT rules; and for the total flow time $\sum C_{i}$ and the total tardiness $\sum T_{i}$ the SPT rule. We can find (even on so small experimental sample) very different optimal rules for the objective functions. The selection of the best (most suitable) rule is then connected with the multicriteria optimization method. But this is not the goal of our paper. Also the application and comparison of more dispatching rules could be easily achieved.

Using the results of the cost-time profile simulation enables us to set an additional scheduling objective function: cost-time investment $C T I$. In our case the best rule was the MS rule (30\% better than the SPT rule; the difference cannot be neglected). The result is somehow expected, while within MS rule the priority goes to the job with the least slack time between due date and current date by taking into account the processing time of the remaining operations. Calculation of the $C T I$ was not a special challenge, but it provides a way to briefly get an impression of how powerful a certain rule can be.

Additionally the total and direct costs were measured, but at the moment we are not using these data in the lean manufacturing efforts. Our goal was the reduction of the cost-time investment to expose the time value of money. So we can recommend to scheduling software developers to add the parallel cost-time profile simulation (with a few additional data related to costs) and include the $C T I$ objective function and scheduling performance measure in their software solutions.

\section{CONCLUSION}

Generally, cost-time profile tools, as well as lean accounting in general, have not been widespread and widely accepted yet by companies, so popularization and proving of their importance are still a big challenge. Modern companies should be value oriented and implement those manufacturing strategies that organize production in such a way that creates more customer value. Value, created for customer, contributes to better results of the company.

This paper is focused on proving that scheduling has essential influence on changes of cost-time investment. Original contribution of the paper is also the suggestion of an additional scheduling performance measure in software solutions. Our future work will be oriented in development of framework with recommendation for applying the cost-time investment measure under different business conditions and goal functions, as well as in combination with other measures such as reduction of material and operation cost.

\section{REFERENCES}

[1] Pan, G.; Feng, D.; Jiang, M. (2010). Application research of shortening delivery time through value stream mapping analysis, Proceedings of the $17^{\text {th }}$ International Conference on Industrial Engineering and Engineering Management (IE\&EM 2010), 733-736

[2] Deif, A. M. (2011). A System Model for Green Manufacturing, Advances in Production Engineering \& Management, Vol. 6, No. 1, 27-36 
[3] Edtmayr, T.; Kuhlang, P.; Sihn, W. (2011). Methodical Approach to Designing Workplaces and Increasing Productivity Based on Value Stream Mapping and Methods-Time Measurement, Transactions of FAMENA, Vol. 35, No. 1, 91-99

[4] Duhovnik, J.; Zargi, U.; Kusar, J.; Starbek, M. (2009). Project-driven concurrent product development, Concurrent Engineering - Research and Applications, Vol. 17, No. 3, 225-236, doi:10.1177/1063293X09343823

[5] Dolsak, B.; Novak, M. (2011). Intelligent decision support for structural design analysis, Advanced Engineering Informatics, Vol. 25, No. 2, 330-340, doi:10.1016/j.aei.2010.11.001

[6] Shah, R.; Ward, P. T. (2003). Lean manufacturing: context, practice bundles, and performance, Journal of Operations Management, Vol. 21, No. 2, 129-149, doi:10.1016/S02726963(02)00108-0

[7] Wilson, L. (2010). How to implement lean manufacturing, McGraw-Hill, New York

[8] Ohno, T. (1988). Toyota production system - Beyond Large-Scale Production, Productivity Press, Portland

[9] Womack, J. P.; Jones, D. T.; Roos, D. (2007). The Machine That Changed the World, (Reprinted edition), Free Press, New York; Simon and Schuster, London

[10] Maskell, B. H.; Kennedy, F. A. (2007). Why do we need lean accounting and how does it work?, The Journal of Corporate Accounting \& Finance, Vol. 18, No. 3, 59-73, doi:10.1002/jcaf.20293

[11] Lanza, G.; Jondral, A.; Book, J. (2011). Capability Assessment and Valuation of the Implementation of Lean Production Methods in Turbulent Environment, Proceedings of the $4^{\text {th }}$ International Conference on Changeable, Agile, Reconfigurable and Virtual Production (CARV 2011), 524-532

[12] Allied Consultants Europe. Operational and lean management survey (2008), from http://www.ace-alliedconsultants.com/publications, accessed on 28-07-2012

[13] Pettersen, J. (2009). Defining lean production: some conceptual and practical issues, The TQM Journal, Vol. 21, No. 2, 127-142, doi:10.1108/17542730910938137

[14] Womack, J. P.; Jones, D. T. (2003). Lean Thinking, Free Press, New York

[15] Malta, J.; Cunha, P. F. (2011). A new approach for cost modelling and performance evaluation within operations planning, CIRP Journal of Manufacturing Science and Technology, Vol. 4, 234-242

[16] Arbulo-Lopez, P. R.; Fortuny-Santos, J. (2010). An accounting system to support process improvements: Transition to lean accounting, Journal of Industrial Engineering and Management, Vol. 3, No. 3, 576-602

[17] Luyster, T.; Tapping, D. (2006). Creating your Lean future state: How to move from Seeing to Doing, Productivity Press, New York

[18] Rother, M.; Shook, J. (2003). Learning to see: Value stream mapping to create value and eliminate Muda, Lean enterprise institute, Cambridge

[19] Wang, L.; Qingmin, Y. (2009). Lean Accounting Based on Lean Production, Proceedings of the International Conference on Management and Service Science - MASS 2009, 1-4

[20] Quarterman, L.; Snyder, B. (2006). The Strategos Guide to Value Stream \& Process Mapping, Enna Products Corporation, Bellingham

[21] Sobczyk, T.; Koch, T. (2008). Method for Measuring Operational and Financial Performance of a Production Value Stream, Koch, T. (Ed.), Lean Business Systems and Beyond, IFIP International Federation for Information Processing, Vol. 257, Springer, Boston, 151-163

[22] Kaplan, R. S. (1983). Manufacturing Performance: A New Challenge for Managerial Accounting, The Accounting Review, Vol. 58, No. 4, 686-705

[23] Cooper, R.; Kaplan, R. S. (1988). Measure Cost Right: Make the Right Decision, Harvard Business Review, Sept.-Oct. 1988, 96-103

[24] Velmurugan, M. S. (2010). The Success and Failure of Activity-Based Costing Systems, Journal of Performance Management, Vol. 23, No. 2, 3-33

[25] Maskell, B. H.; Baggaley, B.; Grasso, L. (2011). Practical Lean Accounting: A Proven System for Measuring and Managing the Lean Enterprise, CRC Press - Taylor \& Francis Group, Boca Raton

[26] Fooks, J. H. (1993). Profiles for performance - Total Quality Methods for Reducing Cycle Time, Addison-Wesley Publishing Company, Reading 
[27] Rivera, L. (2006). Inter-Enterprise Cost-Time Profiling, PhD Dissertation, Virginia Polytechnic Institute and State University, Blacksburg

[28] Chaudhari, G. (2007). Cost-time profile as a tool in value engineering, Value World, Vol. 30, No. $1,1-8$

[29] Lestan, Z.; Brezocnik, M.; Buchmeister, B.; Brezovnik, S.; Balic, J. (2009). Solving the job-shop scheduling problem with a simple genetic algorithm, International Journal of Simulation Modelling, Vol. 8, No. 4, 197-205, doi:10.2507/IJSIMM08(4)2.138

[30] Gen, M.; Tsujimura, Y.; Kubota, E. (1994). Solving job-shop scheduling problems by genetic algorithm, Proceedings of the IEEE International Conference on Humans, Information and Technology, Vol. 2, 1577-1582

[31] Lu, H. L.; Huang, G. Q.; Yang, H. D. (2011). Integrating order review/release and dispatching rules for assembly job shop scheduling using a simulation approach, International Journal of Production Research, Vol. 49, No. 3, 647-669, doi:10.1080/00207540903524490

[32] Alves, T.; Tommelein, I.; Ballard, G. (2005). Value Stream Mapping for Make-to-Order Products in a Job Shop Environment, Construction Research Congress 2005, 1-10 